\title{
Expertise and discretionary bonus decisions
}

\author{
Margaret A. Abernethy \\ The University of Melbourne \\ Department of Accounting \\ Melbourne, Victoria 3010 \\ Australia \\ m.abernethy@unimelb.edu.au \\ Chung-Yu Hung \\ The University of Melbourne \\ Department of Accounting \\ Melbourne, Victoria 3010 \\ Australia \\ chung-yu.hung@unimelb.edu.au
}

\author{
Laurence van Lent \\ Frankfurt School of Finance and Management \\ Department of Accounting \\ Adickesallee 32-34, Frankfurt am Main 60322, Germany \\ L.vanLent@fs.de
}

We are indebted to the hospital for providing us with the data for this study. We greatly appreciate the constructive comments provided by Eddy Cardinaels, Gavin Cassar, Henri Dekker (discussant), Shane Dikolli, Raffi Indjejikian, Chris Ittner, Flora Kuang, Anne Lillis, Paolo Perego (discussant), Bo Qin, Karen Sedatole (discussant), Naomi Soderstrom, Doug Skinner, Jeroen Suijs, Jalal Vafi Sani, and Yachang Zeng and from workshop participants at the Bocconi University, the Cass Business School, the Universidad Pablo de Olavide, Tilburg University, the University of New South Wales, the 2013 AAA Management Accounting Section Meeting in New Orleans, the 2013 European Accounting Association Annual Congress in Paris, and the 2013 Global Management Accounting Research Symposium. 


\title{
Expertise and discretionary bonus decisions
}

\begin{abstract}
We examine the association between managers' expertise and their discretionary bonus decisions in a hospital setting. We hypothesize that high-expertise managers make decisions that encourage cooperation among their subordinates. However, low-expertise managers cannot do so because their lower levels of knowledge, experience, and domain expertise prevent them from having sufficient personal influence to persuade other professionals to cooperate. We find that high-expertise managers make two types of bonus decisions: (1) keep a smaller share of the bonus pool than what they are entitled to retain and (2) allocate the remainder to subordinates more evenly after adjusting for the underlying heterogeneity in their productivity. We also find evidence that high-expertise managers whose bonus decisions reflect their support for cooperation have higher department performance than all other managers.
\end{abstract}

Keywords: discretionary bonus decisions; manager expertise; health care

Data Availability: All data are proprietary. Confidentiality agreements prevent the authors from making the data publicly available. 


\section{Introduction}

We study whether managers with different levels of expertise make different decisions when allocating a bonus pool among department members. Specifically, the managers in our study must decide what share of the bonus pool to keep for themselves and how to allocate the remainder of it among their subordinates. We focus on expertise because recent work in organizational economics suggests that managers differ in the extent to which they are able to build and maintain relational contracts, that is, agreements that cannot be fully specified beforehand or verified afterward and are thus enforced by the desire of both parties to continue the relationship (Helper and Henderson 2014). The effectiveness of many management practices depends on the expertise of managers to develop informal agreements with employees (Gibbons and Kaplan 2015). These studies suggest that heterogeneity in expertise might explain why organizations that seem otherwise very similar to one another make different choices in implementing these competitively significant practices and ultimately report persistent performance differences (Bloom and Van Reenen 2007; Bloom and Van Reenen 2011).

Relational contract theory has been used previously to study discretionary bonus decisions (Baker et al. 1994; Levin 2003), but our approach is somewhat different. We use relational contracts to explain why managers with different expertise vary in their ability to establish long-term cooperation. We then argue that depending on whether cooperation is achieved, bonus allocation outcomes will look different. We also argue that managers who wish to achieve cooperation need to promise payoffs that encourage individuals to work together. Since relational contracts are not enforced by court, managers not only need to persuade others that they will not renege on this promised payoff (i.e., credibility), but they also need to provide clarity to subordinates regarding which actions are deemed cooperative and thus rewarded 
(Gibbons and Henderson 2012). Credibility and clarity are two related problems that both need to be addressed for relational contracts to be effective.

We examine the role of expertise in relation to discretionary bonus decisions in the context of a professional service organization, namely a hospital. In this type of organization, managers who are recognized domain experts ("star physicians") are endowed with the personal influence that allows them to mobilize members of their organization (Mintzberg 1980). Their expertise enables them to solve the two related problems (i.e., clarity and credibility). This allows these managers to build relational contracts to achieve cooperative outcomes.

We predict that high-expertise managers are more adept than low-expertise managers at inducing cooperation, especially among professionals. They do so by adopting a bundle of pertinent management practices that foster cooperative outcomes. In the long run, high-expertise managers are able to create a cooperative working environment wherein each member cooperates with others to increase long-term mutual benefits. However, low-expertise managers are less likely to achieve this cooperative outcome since their low level of domain expertise does not endow them with the personal influence needed to overcome the problems of credibility and clarity.

We expect that managers' effort to promote cooperation leads to the allocation of more generous rewards to subordinates and reward allocations that are more equal (after adjusting for the underlying heterogeneity in subordinates' productivity). These allocation decisions not only reflect the achieved cooperative outcome but also continue to communicate to subordinates that cooperating with each other will generate better results. This reinforced message about the importance of cooperation complements other efforts made by high-expertise managers to 
effectively induce cooperation in the future. As such, the observable equilibrium outcome is that bonus allocations are associated with managers' expertise.

Low-expertise managers might very well be aware that cooperation in performing work tasks can improve outcomes. However, we do not expect them to attempt to achieve cooperation by mimicking the bonus allocation achieved in the departments of their high-expertise counterparts. The bonus allocation decision reflects the cooperative outcome of department members' efforts and also serves as an informal management practice that high-expertise managers use to promote cooperation (Gibbons and Kaplan 2015). The bonus allocation itself does not deliver the cooperative outcome. Instead, what matters is that high-expertise managers can establish the credibility and clarity that will persuade subordinates to respond in a desired manner to a bundle of management practices that together achieve the cooperative outcome. In other words, attempts to use the bonus decision to achieve cooperation without having the domain expertise to mobilize an organization to implement other supporting practices ${ }^{1}$ are expected to be ineffective and indeed personally costly to the low-expertise manager.

We examine these issues by using data from a large Chinese private hospital with multiple clinical departments with physicians appointed as department managers (i.e., heads). Cooperation is a major and salient issue that managers must handle in hospitals. Indeed, in hospitals, perhaps even more so than in other organizations, the production function is based on team work, and achieving cooperation between professionals (physicians and nurses) is essential to patient care and ultimately to performance gains (Gittell 2002; Gittell et al. 2000; Gittell et al. 2010; Pizzini 2010). Within a given medical unit (i.e., department), physicians and nurses

\footnotetext{
${ }^{1}$ Other cooperation-supporting management practices in hospitals may include use of nonfinancial rewards, encouraging horizontal communication or peer review practices that encourage the sharing of patient treatments or outcomes. Although we do not have data to show other practices, the notion of a bundle of management practices has been documented in prior literature (Gibbons and Henderson 2012; Ichniowski et al. 1997; Milgrom and Roberts 1995).
} 
cooperate in devising, implementing, and revising the patient care plan. This practice is particularly important when physicians work across different shifts; it is critical that they cooperate with each other through discussing treatment approaches, especially when they treat the same patients. ${ }^{2}$

Managers in our study have significant authority, which extends to discretion over the allocation of shares in the bonus pool to individual department members. Managers also determine how much of the departmental bonus pool they allocate to themselves (within certain limits). Reward allocation schemes in which the allocator is also a recipient (as with the managers in our hospital) are not uncommon (Meindl 1989). Indeed, agency theory has long touted the idea that by turning agents into residual claimants, many agency problems can be mitigated. Our research site, much like other health care organizations in China, features highpowered incentives that include bonus systems based on generated revenues or profits (Liu and Mills 2005). ${ }^{3}$ Hospitals' financial autonomy has been pushed down to the level of individual clinical departments, with the department managers being the residual claimants of the bonus pool. The bonus pool is based on the department's contribution to hospital profits.

We collect data from the hospital's records on bonus payments to employees in the 20072010 period. Bonus payments to the clinical staff are made monthly, and we have data on 520 unique employees in our sample. The hospital operates a "star physician" system in which the most accomplished physicians are publicly recognized. Using data on these star physicians, together with additional information on prizes and awards, educational background, and 2 For a physician's perspective on the importance of cooperation in hospitals see http://well.blogs.nytimes.com/2015/06/18/when-doctors-dont-talk-to-doctors/? r=0

${ }^{3}$ This practice is common in China following Deng Xiaoping's economic liberalization policy that fundamentally transformed China's health system within the span of a few years. As part of a larger movement of decentralization and granting of financial autonomy to local governments and state-owned enterprises (SOEs), autonomous health care providers emerged as a significant force. Although subsequent reforms aimed to reduce the perverse effects of high-powered incentives on the provision of health care services, bonus systems on generated revenues are still commonplace in the compensation package of hospital workers. 
professional experience, we construct measures of domain (i.e., medical) expertise for each physician in our sample (and consequently for each manager in our sample). We use these measures of medical expertise as proxies for the ability of the physician-manager to build relational contracts.

Our study's main contribution is twofold. We document that reward (i.e., bonus) allocations reflect variation in a manager's expertise. In addition, we show that the reward allocation in conjunction with a manager expertise is associated with performance outcomes. Our evidence indicates that managers with high (low) expertise systematically have a smaller (bigger) proportion of the departmental bonus pool than they are entitled to. What's more, managers with high (low) expertise have a more (less) equal bonus distribution after adjusting for individual differences in productivity; that is, the individual incentives provided to their subordinates are more muted. We demonstrate that high-expertise managers with bonus allocations that reflect cooperation-supporting practices have higher performance outcomes than all other managers. This latter finding adds to the literature on managerial ability (Demerjian et al. 2012; Kaplan et al. 2012) and offers evidence that ability can explain why management practices are implemented differently in organizations that appear otherwise very similar yet have persistent differences in their performance. Whereas earlier studies have focused mostly on senior executives and on between-firm effects, our paper examines heterogeneity within one organization and shows that variety in domain expertise is reflected in compensation outcomes at the department level as well as in the ultimate performance of a department.

In addition, a long-standing interest exists among economists for explaining the use of incentive systems in organizations (Holmstrom 1979; Jensen and Meckling 1976). There are, however, costs associated with using incentives to motivate an agent's effort (Ellingsen and 
Johannesson 2008; Holmstrom and Milgrom 1994; Sliwka 2007). Our findings suggest that highexpertise managers understand the subtle role that incentives can play in promoting long-run cooperation and thus are adept at building relational contracts. Adding to the literature on the design of incentives, our study indicates that managers' ability to build relational contracts is associated with the use of discretionary bonus decisions to promote cooperation. Further, we find that high-expertise managers' compensation decisions have different outcomes compared with those of low-expertise managers. This evidence supports recent research showing that relational contracts are a major determinant of long-run cooperation (Bloom et al. 2013; Bloom and Van Reenen 2007; Gibbons and Henderson 2012).

Finally, an important related stream of literature has examined discretionary bonus decisions by managers in the context of subjective performance evaluation. This body of work emphasizes potential behavioral biases when superiors evaluate the performance of employees (Bol 2011; Bol and Smith 2011; Moers 2005). ${ }^{4}$ Although this research has increased our understanding of behavioral biases in bonus decisions, we are interested in documenting the bonus allocation of managers who encourage cooperative team work. Thus, the bonus decision, while important in its own right in the compensation of employees' effort, also reflects the extent to which managers can develop and maintain relational contracts to support long-run cooperation. Our contribution to this literature, then, is that some of the behavioral biases (e.g., centrality, leniency) in bonus decisions that have been characterized as judgment errors might actually serve a deeper economic role (see also, Prendergast and Topel 1996).

Our study has potential implications for practice. We highlight how in complex contracting environments, bonus decisions might reflect a myriad of management practices that

\footnotetext{
${ }^{4}$ Note that the behavioral biases associated with confrontation costs (i.e., psychological disutility of being thought of as a "bad" person) do not explain the difference in reward allocation decisions between high- and low-expertise managers.
} 
high-expertise managers take to support cooperation and how they can be used as a tool for managers to reinforce cooperation. We demonstrate that performance improvements may ensue, which strengthens the case for organizations to invest in ways that help managers establish their bona fides with subordinates. In our setting, the hospital awards some physicians the honor of being a "star physician" which greatly raises their profile among their peers and allows them to more effectively communicate the importance of certain clinical practices and increases their credibility when it comes to convincing their colleagues of how things should be done. Our findings also suggest that simply telling managers to follow the observable (bonus-related) actions of their well-regarded colleagues is unlikely to yield the desired outcomes.

\section{Prior literature and hypothesis development}

Substantial evidence supports the idea that managers matter to the performance of the firm (Abernethy and Wallis 2018; Adams et al. 2014; Bertrand and Schoar 2003; Graham et al. 2013). What successful managers do to improve performance is less well understood (Bandiera et al. 2011). This particular question has been the focus of recent work in organizational economics. These studies observe that seemingly similar organizations can have persistent performance differences because nontrivial heterogeneity exists in the extent to which managers are able to implement "competitively significant management practices" (Bloom and Van Reenen 2007; Gibbons and Henderson 2012, 2013).

Many of these management practices rely on establishing relational contracts, which makes mimicry difficult because their successful implementation may depend on managers' ability to develop a shared understanding within the organization about what is expected to generate results. For example, to induce cooperative behaviors, which cannot be easily done by an incentive contract, managers must clarify to subordinates what defines cooperation according 
to their specific working environment and how cooperation yields mutual benefits. Additionally, managers need to convince the subordinates that they will not renege on promised payoffs but reward cooperative effort accordingly. As Gibbons and Henderson (2012) highlight, credibility and clarity are related problems that managers encounter when developing relational contracts. However, managers can solve these problems when they have personal influence to persuade the organization to follow their lead. In professional service organizations (e.g., hospitals), the ability to mobilize specifically depends on the respect, admiration, and even awe, the manager has garnered among colleagues for his or her professional skills, that is, his or her domain expertise (Mintzberg 1980).

Cooperation is viewed as a behavior that is desirable but difficult to motivate (Gibbons and Henderson 2012; Tabellini 2008). Indeed, cooperation between medical professionals is one of the major determinants of quality and efficiency outcomes for patients treated in hospitals (Gittell 2002; Gittell et al. 2000; Gittell et al. 2010). In a hospital setting, patient cases vary considerably and managers cannot specify all possible solutions to treating the patient. Thus, they cannot easily judge the contribution of each professional in the treatment process or the appropriateness of the medical treatment. Relational contracts shed light on problems that managers encounter in encouraging cooperation in this kind of setting, and the theory suggest that managers' ability to build relational contracts largely differentiate the outcomes that they can achieve. Specifically, Gibbons and Henderson (2012) show the two possible outcomes (i.e., cooperative and noncooperative equilibria) and suggest that not all managers can achieve the 
cooperative outcomes. The distinction is helpful in characterizing the expected management practices (e.g., reward allocation) with and without relational contracts in place. ${ }^{5}$

When relational contracts are not built, individuals are not cooperative and exert effort to maximize their own short-term benefits. In contrast, when relational contracts are developed, individuals cooperate with each other to maximize the long-term collective benefits. The main idea behind relational contracts is that individuals anticipate that noncooperative actions will be punished by the other party through refusal to work together in the future. Despite individuals being prone to maximize the short-term benefits by working noncooperatively (i.e., break the informal cooperation agreement), cooperation can be achieved because they do not want to forego the long-term gain of cooperation. In other words, if individuals are sufficiently patient, then the threat of punishment motivates cooperative actions and prevents players from choosing the short-run benefits of defecting. Nevertheless, cooperation outcomes can be fragile because all parties involved need to be fully informed about the benefits and costs of cooperation, defection, and punishment. And perhaps more importantly, all players also need to understand what actions constitute cooperative behavior and what actions the other party will perceive as defection. When relational contracts are built to foster cooperation, overall performance is predicted to be higher compared to a setting without relational contracts that support cooperation; this, in turn, increases the bonus pool available for compensating the players. ${ }^{6}$

Reward allocation is not only part of a bundle of management practices but will also reflect the (non-) cooperative outcome. In particular, under the cooperative outcome all players

\footnotetext{
5 The cooperative outcome and noncooperative outcomes also refer to the repeated and one-shot games, respectively. Under a one-shot game scenario, players may work together for more than one period, but their strategy is formed on a period-by-period basis.

${ }^{6}$ This conclusion is reached under the assumption that - as in our hospital setting-cooperation is important for performance.
} 
choose to work together and contribute equally to increase the joint outcome. ${ }^{7}$ Thus, we expect that a reward allocation scheme reflecting cooperation-supporting management practices yields a more even distribution of rewards among department members. In addition, subordinates' cooperative efforts should yield persistent performance improvements. For example, an effective collaboration between physicians and nurses can fundamentally improve the quality of patient care and reduce morbidity and mortality. In that sense, we also expect that the manager provides more generous rewards to subordinates to compensate them for cooperative effort that has permanent impacts on organizational performance.

Furthermore, over time we expect that these reward allocation patterns reinforce the cooperative behavior. When managers distribute bonuses to each physician within their department more evenly, the individual physicians are more willing to engage in helping colleagues (Itoh 1991) because doing so will not harm their compensation. The managers' generosity of taking a smaller share of the pool (i.e., leaving more to their subordinates) illustrates the value of cooperation to generate mutual benefits and in turn bolsters the long-run cooperation. ${ }^{8}$ As a result, overall performance is likely to benefit. Thus, over the long run, reward allocations in which the manager keeps a lower fraction of the pool and allocates the remainder to department members more evenly becomes part of a bundle of informal

\footnotetext{
${ }^{7}$ Heterogeneity may exist in job functions, professional specialty, ability, or seniority among players. This heterogeneity represents the underlying differences in players' productivity (i.e., their potential to contribute to the joint outcome). When we talk about the "even" contribution of players here, we mean that their contribution is even after we take into account their potential to contribute. We discuss this matter further in Section 3.

${ }^{8}$ The idea that managers use "generosity" to communicate their intentions to employees is not limited to our research setting. According to a recent report by the Financial Times (August 4, 2016), the CEO of Majestic Wines, Mr. Rowan Gormley, shares his $£ 7$ million (approx. US\$9 million) stock bonus with his employees, with the intention "that by forgoing his share of the scheme, he will encourage his staff to reach the 2019 target and boost morale." Indeed, Mr. Gormley is quoted in the report to believe "It's as much to do with emotion as it is to do with rational thinking. And the emotion you try to engender is: We are in it together, we benefit together." The report is available at http://www.ft.com/cms/s/0/b730b086-5963-11e6-8d05-4eaa66292c32.html\#axzz4H1gYRZKA.
} 
management practices that complement any other efforts the manager makes to promote and sustain cooperation.

The adoption of competitive management practices is constrained by managers' ability to develop relational contracts. Low-expertise managers lack the credibility to use the broader palette of "informal management" practices (Gibbons and Kaplan 2015) to foster cooperation. Consequently, these managers cannot forge the relational contracts necessary to attaining the cooperative outcome and find themselves in the situation in which cooperation cannot be achieved. Instead, they use individual incentives to motivate employees to do their job. Therefore, high-expertise managers are predicted to be associated with the cooperative outcome, but low-expertise managers are associated with the noncooperative outcome.

In our setting, our conjecture is that high-expertise managers not only have a better understanding of the organizational context than other managers, but they also command the kind of professional respect from their colleagues that allows them to select and implement practices that encourage cooperation. Since these managers build relational contracts that allow them to attain the cooperative outcome (equilibrium), we expect their reward allocation decisions are more likely to reflect this cooperative outcome and reinforce it. Thus, when high-expertise managers decide how much of the bonus pool to allocate to themselves (within well-specified constraints), they will be more generous to department members as part of the payoffs associated with each individual playing the cooperation strategy for the long-term mutually beneficial relationship. Further, in allocating the remaining bonus pool to the department members, they reward each one more evenly. Not only do these choices reflect the equilibrium outcome, but they both also have the potential to clarify and reinforce the value of cooperation in the team to the department members. 
Indeed, relational contracting highlights the possibility that managers might mute incentives to achieve cooperation rather than devise schemes that reward joint or team performance directly (Bouwens and Van Lent 2007; Bushman et al. 1995; Keating 1997). Furthermore, several studies have raised the possibility that increasing the explicit incentives for cooperation can signal to the agents that the principal does not believe that they are willing to cooperate in their own right (Bénabou and Tirole 2003; Falk and Kosfeld 2006; Sliwka 2007). If the manager takes the maximum possible bonus for himself or herself, the implication is that sharing with the team is not a priority; consequently, team members may plausibly infer that cooperation within the team is no longer a pertinent concern to this manager. Relatedly, if the bonus allocation to team members is determined by individual performance in a given period, team members might be unwilling to help each other to deal with adverse temporary shocks to individual productivity.

Thus, we explore the association between the expertise of managers and reward allocations. We summarize our expectations as follows:

H1: The expertise of managers is negatively associated with the share of the bonus pool they allocate to themselves.

H2: The expertise of managers is negatively associated with the extent to which managers differentiate among subordinates in their bonus allocation.

Differences in the type of managers have been identified as a plausible source of persistent performance differences in earlier work (Gibbons and Henderson 2013). Although high-expertise managers have a better sense of how to induce cooperation, they may still face organizational barriers and other factors in acting on their expertise. In other words, managers' expertise and their cooperation-supporting practices may not be perfectly correlated with each other, and we may observe that some high-expertise managers do not implement management practices to promote or maintain cooperation. Nevertheless, we expect that the performance 
effect will be the joint outcome of managers' expertise and cooperation-supporting management practices. In particular, performance of the clinical department will be higher in departments led by a manager with high expertise and whose reward allocations reflect that he or she has forged the relational contracts needed for a cooperative outcome to emerge. Hypothesis 3 summarizes our expectation:

H3: The performance of departments in which the managers have high expertise and their discretionary bonus decision reflects effective cooperation is higher than the performance of all other departments.

\section{Research Site, Data, and Summary Statistics}

Our data are taken from the company records and public websites of a large general hospital located in China. The hospital is the only general health facility situated in a largely rural area. It has obtained the highest classification in China's ranking system of health care providers. Accordingly, it offers a broad array of medical services organized in 34 clinical departments. These clinical departments are further divided into medical, surgical, and medical support. ${ }^{9}$ Clinical departments are managed by a physician. Managers have broad-ranging decision-making authority, and their discretion is largely the same across departments. Departments are treated as profit centers, and all patient revenues are accordingly allocated to the contributing departments as earned. Direct costs are incurred where expended. ${ }^{10}$ Hospital revenues derive from both outpatient (40 percent) and inpatient (60 percent) services. The hospital has experienced significant growth in recent times, and during the sample period (20072010) its revenues have increased by 186 percent.

\footnotetext{
${ }^{9}$ Medical departments include Gastroenterology, Pediatrics, Nephrology, and Neurology. Surgical departments include Neurosurgery, Obstetrics and Gynecology, Orthopedics, Stomatology, and Urology. Examples of medical support departments are Pathology, Radiology, and Ultrasonography.

${ }^{10}$ Each department contributes to indirect hospital overheads although we do not know how this is determined.
} 
We collect data on the clinical staff, which includes both physicians and nurses. The number of clinical staff members in our sample varies from month to month between 480 and 496 individuals [consisting of 230 (290) unique physicians (nurses)]. The observed turnover in the data is very low perhaps because the hospital is the top clinical facility in a sprawling geographical region. ${ }^{11}$ The clinical staff receives a fixed salary as well as a bonus, which is payable on a monthly basis. Individual bonuses are shares in the department's bonus pool, which depends on the department's monthly profit. Monthly bonus allocations are discretionary, and the decision is delegated to the manager of the department. No formula exists for determining bonuses within departments, and the hospital does not track individual performance indicators for either physicians or nurses. ${ }^{12}$ Nevertheless, hospital management emphasizes that department managers should reward their department members according to their contribution to the department. Department managers are the "residual claimant" of the department's bonus pool, in the sense that their share in the pool equals the remainder after all employees have received their portion, provided the managers' share does not exceed 350 percent of the average bonus of all the employees in the department.

The hospital's records provide us with accounting data on each department's monthly profits and revenues as well as with data on monthly salary and bonus payment for each clinical staff member. We also obtain basic personnel data on age, tenure, and gender. The hospital records only include information for the department members who are formally employed by the hospital. Only these individuals have a stake in the bonus pool. We supplement this data by hand-collecting information from the hospital's website regarding personal details about

\footnotetext{
${ }^{11}$ Nearly 90 percent (464 out of 520) of unique employees stay in the hospital over the sample period.

${ }^{12}$ There is no nondisclosure policy in the hospital regarding bonus payments. How much bonus information is revealed is at the managers' discretion. Therefore, we assume that the bonus disclosure policy within departments is related to the managers' intention to induce cooperation. High-expertise managers have incentives for higher information transparency about the bonus allocation than low-expertise managers.
} 
physicians, such as their educational background, prizes, and memberships in medical associations. Some physicians are publicly recognized on the hospital's website as "stars" (e.g., physicians with greater expertise in a given specialty). Star physician status is conferred by the hospital, and these physicians have an official profile picture on the hospital's website in which they are wearing a red sash (non-stars have no such sash). Prizes and membership are selfreported, but physicians have an incentive to be complete in their CVs because these external validations likely attract patients and generate revenues. All physicians who participate in the bonus pool are covered on the hospital website.

Table 1 presents descriptive statistics on the departments and on the salary and bonus of managers. The average size of the clinical departments is 16 physicians and nurses. Bonus payments are an economically significant part of an employee's compensation. Indeed, measured at the department level, the ratio of bonus to salary is 2.5. The reported statistic on HeadBonSlice (the manager's bonus share) shows that department managers, on average, allocate 21 percent of the bonus pool to themselves. This allocation is below the (unreported) maximum allowable share of approximately 26 percent. Adhering to a confidentiality agreement with the hospital, we have rescaled the data for department profits (revenues) to preserve the anonymity of the research site. Consequently, the reported statistics for these (and related) variables (such as the size of the department's bonus pool) cannot be taken at face value. ${ }^{13}$

\section{Empirical Models and Results}

\subsection{Are discretionary bonus allocations different in departments led by managers with high expertise than in departments with managers with low expertise?}

\footnotetext{
${ }^{13}$ We have access to the actual data for the empirical analysis; the rescaling of variables is only limited to the summary statistics in Table 1. The presentation of the other tables is not affected because we use actual data to conduct the empirical tests.
} 
We begin by testing how the discretionary bonus decisions of managers vary with their expertise (Expert). Our regressions have the following generic specification,

$$
\text { DiscBonus }_{i t}=\gamma \text { Expert }_{i}+\boldsymbol{X}_{i t}^{\prime} \beta+\eta_{t}+\varepsilon_{i t}(1)
$$

where $i$ is an index across departments, and $t$ is an index across months. The variable DiscBonus is either a proxy for the manager's own bonus allocation or a proxy for the distribution of bonus payments to other department members. Under our hypothesis, bonuses do not just reflect differences in contribution between managers and across department members; they are also used to clarify and reinforce the importance of cooperation. For our tests, it is imperative that we tease out the part of the bonus that reflects the managers' effort to promote cooperation from the part that simply reflects heterogeneity in department members' contribution. ${ }^{14}$ We do so by using a given individual's salary as a proxy for that person's contribution. ${ }^{15}$

Individual salary is usually associated with the responsibility associated with the position and is not subject to temporary events that affect individual productivity; that is, individual salary is relatively fixed. Thus, the variations in department members' salaries approximately reflect the underlying heterogeneity in the contribution that they are able to make. The individuals' contribution-adjusted bonuses reflect the managers' effort to promote department members' cooperation. The manager's contribution-adjusted bonus captures how much the manager is willing to share with department members, and thus it reinforces the value of cooperation within the department. The contribution-adjusted bonus allocation among

\footnotetext{
${ }^{14}$ We do not have a direct measure of individual performance (e.g., the number of patients treated by a given physician) and hospital policy does not specify any particular performance measure.

${ }^{15}$ Salary is a reasonable approximation of an individual's contribution and is assumed to be time-invariant. While an individual's performance may be volatile, salary represents the fixed part of the contribution, which we term persistent contribution.
} 
department members reflects the extent to which managers wish to ignore temporary productivity shocks that might harm cooperation. ${ }^{16}$

The variable of interest, Expert, is a composite measure based on seven indicators of a physician's expertise. ${ }^{17}$ Principal component analysis reveals three underlying dimensions of Expert, corresponding to prestige (prizes won, receiving recognition as a star physician), experience (tenure, age), and education (ranking of school at which the medical degree was obtained). We have raw expertise scores for every physician in our sample. Managers' expertise is the sum of their scores across the three dimensions. Given our data, a manager's expertise is quasi-time-invariant, and our measure, Expert, is the average of managers' expertise over the sample period. Appendix B provides more details.

We include a number of control variables. A $\mathrm{K} \times 1$ vector of control variables, $\boldsymbol{X}_{i t}$, includes the current period's department profit (DepProfit), the size of the department (DepSize), the ratio of physicians to other personnel (PhyRatio), the average department bonus-to-salary ratio (DepBonSalRatio), and indicator variables that are equal to unity when the department is surgical (DepSurg) or medical (DepMed), respectively, and zero otherwise. We also include the departmental task interdependence (Interdepend) developed by Pizzini (2010). This variable captures the need for cooperation driven by the nature of department task rather than the expertise of managers. Our set of control variables collectively aims to absorb the effects of current performance on the bonus pool, variations in personnel size and composition between

\footnotetext{
${ }^{16}$ Note that rewarding individuals differently (to reflect variations in their underlying potential to make a contribution) is not at odds with the goal to encourage cooperation. The literature on team-based incentives has argued that pay schemes that provide equal shares to group members is appropriate to encourage cooperation in homogenous groups (Bushman et al. 1995; Hamilton et al. 2003; Knez and Simester 2001; Pizzini 2010). When groups are heterogeneous, such as when departments have both experienced and junior physicians, pay schemes should reflect these differences in underlying productivity.

${ }^{17}$ These indicators capture physicians' medical expertise, which comes from the experience and previous formal medical training, as well as the acquisition of new knowledge from participating in professional association. The measure of expertise represents the extent to which physicians understand the standard of high-quality medical treatments.
} 
departments, and potential departmental differences in incentive power (measured as bonus-tosalary ratios), tasks, clinical complexity, and risk. ${ }^{18} \eta_{t}$ denotes year fixed effects, controlling for secular trends in general economic conditions.

A cause of potential concern is the role of unobserved heterogeneity in our empirical analysis. The question arises as to whether the clinical departments are truly comparable even after controlling for types of department (e.g., medical, surgical, and support departments). Unobserved and observed heterogeneity may remain in patient mix, the role of employees, and the potential contribution of employees to the department. One potential solution is to use department fixed effects, but the fixed-effects estimator washes out the estimate of the coefficient on the variable of interest in the main analysis (Expert) because this variable is quasitime-invariant.

As an alternative to fixed effects, we implement Wooldridge's (2000, p. 332) correlated random effects approach where appropriate. This approach includes the department (time series) averages of the time-varying variables as additional regressors in the regression equation and allows for a time-constant explanatory variable. Intuitively, this approach allows the timeconstant variable to be correlated with the department-average level of the time-varying variables. Wooldridge (2000) shows that estimating the regression by random effects yields the same estimate on the time-varying variables as estimating by fixed effects but allows for having a time-constant variable of interest, for which we can also obtain an estimate.

Therefore, for the time-varying variables, such as DepProfit, the analyses include the within and between estimates, which reflect the effect within a given department and across

\footnotetext{
${ }^{18}$ Ideally, we would like to control for differences in the wealth of the department managers. Wealthier managers might choose to be simply benevolent (or generous) without the explicit objective of using their discretion to encourage cooperation. We do not have data on the wealth of individual physicians. To the extent that the physicians' wealth derives from the compensation received at the hospital, however, our contribution adjustment partially corrects for accumulated wealth differences.
} 
departments, respectively. For the time-constant variables, most notably for managers' expertise (Expert), the estimate only exploits variation between departments.

In sum, we estimate a modified version of Equation 1 using a random correlated effects (RCE) model as follows:

$$
\text { DiscBonus }_{i t}=\gamma \text { Expert }_{i}+\boldsymbol{X}_{i t}^{\prime} \beta+\overline{\boldsymbol{X}}_{i}^{\prime} \delta+\eta_{t}+\varepsilon_{i t}\left(1^{\prime}\right)
$$

Where $\overline{\boldsymbol{X}}_{i}$ is a $\mathrm{K} \times 1$ vector of department time-series averages of control variables. The parameter $\beta$ refers to the within estimates and $\delta$ to the between estimates. We report standard errors clustered by department throughout. Our coefficient of interest is $\gamma$.

Our main specifications relate our preferred (composite) measure of expertise (Expert) to various proxies of the manager's own bonus allocation. These latter proxies vary in the way we attempt to adjust for differences in contribution (i.e., as measured by their salary level) among the managers, which would yield variations in bonus allocation even absent any action by the managers to support cooperation. In addition, we decompose Expert into its underlying parts, namely, measures of the manager's expertise in terms of prestige, experience, and education.

Table 3 (columns 1-3) reports the empirical estimates of Equation (1') using our preferred composite measure, Expert. We find consistent results across the three different proxies for the manager's own bonus allocation. In column 1, we measure the manager's own contribution-adjusted bonus by computing the share of the manager in the department's bonus pool and adjusting it for the manager's contribution as measured by his or her salary. We find a significant negative association on Expert $(\gamma=-0.868$, s.e. $=0.218)$ with $p<0.01$ (two-tailed) and one standard deviation of managers' expertise is associated with a 37 percent decrease in managers' adjusted bonus. Thus, high-expertise managers allocate significantly lower contribution-adjusted bonuses to themselves compared with low-expertise managers. Rather than 
contribution-adjusting the dependent variable directly, in column 2, we regress the share of the manager in the department's bonus pool onto Expert as well as the proxy for the manager's contribution based on his or her salary (HeadSalSlice). We also include the full set of control variables. Once again, we find a significant negative association between Expert and the manager's own bonus allocation $(\gamma=-0.902$, s.e. $=0.221)$. The coefficient estimates $(\gamma)$ reported in columns 1 and 2 are very similar, which provides some assurance that our procedure of contribution-adjusting the dependent variable is not driving our results.

In column 3, we take yet another approach to adjust the manager's own bonus for contribution differences. We no longer include salary as an independent variable on the righthand side of the regression but instead, as a first step, regress the bonus payment of every individual in the sample onto their salary and our full set of control variables $\boldsymbol{X}_{i t}$ with department fixed effects. The unreported empirical results show that the explanatory power of this regression is good (Adj. $\mathrm{R}^{2}=55.09$ percent; $\left.F(7,519)=179.30, p<0.01\right)$. We use the residual of this regression, which we interpret once more as the contribution-adjusted bonus (namely, the part of the bonus payment that cannot be explained by the manager's contribution as reflected in the salary or the control variables). Column 3 reports the regression results of these residuals (for the heads only) onto Expert and the regular set of control variables. Since the first-step regression includes department fixed effects, we apply pooled OLS to this analysis. Including the regular set of control variables is necessary to control for departmental differences because we only use the residuals for the subsample of managers from the first step (which is computed using the full sample of all physicians). As before, we find a significant negative association between the manager's expertise and the contribution-adjusted bonus allocated to himself or herself. 
Finally, we repeat the analysis in column 1 but now use a decomposed measure of Expert that allows us to estimate the separate effects of the manager's expertise corresponding to prestige, experience, and education. We find a negative association for all three component parts of Expert, with estimates of $\gamma$ varying between -0.678 and -1.355 , although the statistical significance varies for each. Overall, the results in Table 3 support the prediction summarized in hypothesis 1 that managers with high levels of expertise will allocate a lower bonus payment to themselves.

In Table 4, we present our tests of hypothesis 2 . We are interested in examining whether Expert is associated with the extent to which the bonus allocation decision reflects the manager's effort to promote cooperation to department members. The bonus allocation should be such that it is relatively immune to individual time-varying performance but captures the members' persistent contribution to the department. However, we postulate that in our setting there are at least two allocation distributions that reflect cooperation. We consider both possibilities in our empirical tests. First, the salary of employees captures their underlying productivity, and we use it as a proxy for their persistent contribution to the department. Thus, we compute for each subordinate the contribution-adjusted bonus by subtracting from his or her share in the bonus pool the share expected based on his or her persistent contribution. We then compute for each department $i$, for each month $t$ the standard deviation across subordinates of their contributionadjusted bonus. If bonuses are truly allocated according to contribution, then little variation among department members should exist after adjustment for their persistent contribution. ${ }^{19}$

\footnotetext{
${ }^{19}$ We attempt to capture the extent to which managers minimize the temporary shocks to individual productivity at the department level. Thus, we first compute contribution-adjusted bonus for each employee and then use the standard deviation across employees' contribution-adjusted bonus as the proxy for the allocation rule for persistent contribution. Taking the difference in the standard deviation between the two distributions-one for each employee's bonus and the other for each employee's salary-does not reflect the aggregation of individual productivity shocks at the department level.
} 
We also use an alternative approach to recognize that managers could distribute a bonus among employees based on the simple rule of equality, which also restricts the effect of productivity shocks on individual bonuses. Several commentators on bonus practices in the Chinese health care system have indicated that a strong convention exists to distribute rewards equally among employees (Cooke 2004; Liu and Mills 2005). Accordingly, we do not adjust bonus payments for contribution (proxied by fixed salary) but determine the difference between the actual bonus payment of a subordinate and his or her share if the pool had been equally distributed. We then compute for each department $i$ and for each month $t$ the standard deviation across department members of this difference. To the extent that bonuses are allocated equally, this standard deviation should be lower.

Table 4, column 1 reports the estimates of Equation (1') using our measure Expert and our proxy for the manager's bonus decision relating to subordinates. We find a significant negative association $(\gamma=-0.165$, s.e. $=0.063)$ at the 1 percent level (two-tailed) consistent with the expectation in hypothesis 2 . One standard deviation of managers' expertise is associated with a 24 percent decrease in the dispersion of subordinates' adjusted bonus. When we decompose Expert into measures of the managers' expertise regarding prestige, experience, and education, we continue to find significant negative coefficient estimates for experience and education and a negative but nonsignificant coefficient for prestige.

Next, we report the results when using the equality rather than the contribution-based measure. As reported in columns 3 and 4, we do not find evidence that Expert is associated with equality-based bonus dispersion. For that reason, it is unlikely that an equality-based bonus decision reflects the management practices that are used to encourage cooperation among department members. 
We recognize that monthly bonus allocations are likely to be serially correlated and use the panel structure of our data set to take care of this correlation. When we estimate Equation $\left(1^{\prime}\right)$, standard errors are clustered by department, such that we allow for an arbitrary correlation structure for all observations within the same department. We also collapse the monthly data by taking the department average of all variables over the sample period and conduct the analyses on the reduced sample of department averages. The results are reported in Table 5. We continue to find significant negative coefficient estimates for Expert in relation with managers' own contributed-adjusted bonus and the deviation from the contribution-based principle in subordinates' bonuses. Those coefficients have similar magnitude with those in Tables 3 and 4, which also validates the use of a random correlated effects model. Therefore, our inferences regarding hypotheses 1 and 2 are unaffected.

\subsection{Performance consequences of managers' expertise jointly with their bonus decisions}

The analyses in the previous section together support the notion that reward allocations in departments led by high-expertise managers are different compared with those in departments led by low-expertise managers. Specifically, high-expertise managers have a lower (contributionadjusted) bonus allocated to them, and the allocation of bonuses to employees are more consistent with the contribution-based principle. Under our hypotheses 1 and 2 , this pattern in the data is consistent with the discretionary bonus decisions of high-expertise managers reflecting their efforts to clarify and reinforce the value of cooperation. Under hypothesis 3 , we expect that the performance of departments in which the manager (1) has high expertise and (2) supports the importance of cooperation among department members through our two types of bonus decisions should improve to a larger extent than the performance of all other departments. 
We investigate this prediction using the following specification, as before, in a random correlated effects framework,

$$
\begin{aligned}
& \Delta \operatorname{Perf}_{t}=\lambda_{1} \mathbf{1}\left(\text { Expert\&Coop }_{i t}+\lambda_{2} \mathbf{1}\left(\text { Expert\&NoCoop }_{i t}+\lambda_{3} \mathbf{1}(\text { NoExpert\&Coop })_{i t}+\right.\right. \\
& \boldsymbol{X}_{i t}^{* \prime} \delta+\overline{\boldsymbol{X}}_{i}^{* \prime} \gamma+\eta_{t}+\varepsilon_{i t}(2)
\end{aligned}
$$

where $\Delta P e r f$ is the scaled or unscaled change in the departmental revenues, measured over one month (columns 1-3), 3 months (column 4) and 6 months ahead (column 5), respectively. ${ }^{20} \mathrm{We}$ also report the one month-ahead change in department profit in column 6 , but caution that this measure needs to be interpreted with care as profits are subject to arbitrary cost allocation of indirect costs in the hospital. The vector $\mathbf{X}^{*}\left(\overline{\boldsymbol{X}}_{i}^{\prime}\right)$ contains the set of (time-series averages of) control variables for this regression, which includes all variables previously defined in $\mathbf{X}$. The control variable, DepSize, is not included in the regressions that have a scaled dependent variable (i.e., change in performance scaled by the number of employees or percentage change in performance).

Our key variable of interest is $\mathbf{1}$ (Expert\&Coop), which is an indicator variable constructed to identify the manager who has high expertise and uses both types of bonus decisions to support cooperation. High-expertise managers are those whose score is above the median on Expert. Likewise, we define managers who encourage cooperation as those whose own contributed-adjusted bonus (the deviation from the contribution-based principle in subordinates' bonuses) is below (below) the sample median. We construct two other variables to capture the group of high-expertise managers who do not use both types of bonus decisions to support cooperation (i.e., 1(Expert\&NoCoop)) and low-expertise managers who do use both types of bonus decision to foster cooperation (namely, 1(NoExpert\&Coop)). Effectively, by

\footnotetext{
${ }^{20} \mathrm{We}$ winsorize the performance variables, $\Delta P \operatorname{Perf}$, at the $5^{\text {th }}$ and $95^{\text {th }}$ percentile.
} 
including these three indicator variables together in our regression, we estimate the effect of expertise and cooperation-supporting bonus decisions of each of these groups compared to the reference group of low-expertise managers who do not use bonus decisions for cooperation.

Table 6, panel A, reports the estimation results for Equation (2). Focusing our attention to the variable that captures the group of our main interest (Expert\&Coop), we find that across all performance proxies, these managers have significantly higher future performance (compared with the reference group). For example, in column (3), the estimated coefficient equals 0.031 $(p<0.05)$, implying that high-expertise managers with cooperation-supporting bonus decisions have about 16 percent of a standard deviation higher one month ahead revenue growth than managers in the reference group (with low expertise and no cooperation supporting bonus decisions). Similarly, the coefficients in columns 4 and 5 suggest that the Expert\&Coop managers, compared with reference group managers, have approximately 25 percent of a standard deviation higher future revenue growth (over 3 and 6 months), respectively.

For the remaining two groups (Expert\&NoCoop; NoExpert\&Coop), we do not find a significant difference in future revenue performance compared with the reference group of lowexpertise managers who do not use bonus decision to support cooperation.

Our specification can also be interpreted to present the "stand-alone" (i.e., main) effects of expertise and cooperation-supporting bonus decisions on performance. In this light, we find very little evidence that having high-expertise managers (who do not use bonuses to support cooperation) is positively associated with future revenues (see the row Expert\&NoCoop). However, we do find that these managers have significantly higher profits (compared with lowexpertise managers). Similarly, we find no significant stand-alone (main) effect of cooperation on future revenues (see the row NoExpert\&Coop). In this case, however, the point estimates 
appear to be somewhat economically meaningful, but they are noisily estimated preventing a significant effect. Having said that, when we consider the main effect of cooperation-supporting bonus decisions on future profits, we find some evidence of a positive association.

Recall that hypothesis 3 predicts that compared with all other managers, high-expertise department managers who use cooperation-supporting bonus decisions will have higher performance. We test this prediction directly in panel B of table 6 , in which we report the estimates of a shortened regression. This regression creates a reference group that includes all managers except those in the Expert\&Coop group (i.e., drops Expert\&NoCoop and NoExpert\&Coop groups). The estimated coefficient on Expert\&Coop in panel B of Table 6 represents the difference in future performance of high-expertise managers who make cooperation-supporting bonus decisions compared with all other managers. We find a positive and significant coefficient across all different performance measures, consistent with our expectations. Together the findings in table 6 provide support for our prediction that performance improvements are a potential outcome for high-expertise managers, who appear to be building relational contracts through their bonus allocation decisions. Indeed, if they succeed, by their (bonus and other) actions, to promote cooperation, economically meaningful performance differences can arise compared with other managers who do not have the expertise or ability to sustain cooperative relationships in their department.

\section{Discussion and Conclusions}

One of the most interesting themes in the managerial economics literature is that some pervasive organizational practices are seemingly difficult to rationalize (Bloom and Van Reenen 2007; Gibbons and Henderson 2012). In a well-known example, Prendergast and Topel (1996) provide economics-based explanations for why firms may allow managers to exercise favoritism 
in the allocation of benefits to their protégés. We offer our evidence in the spirit of this broader literature and document how a seemingly hard-to-understand managerial action, namely, sharing one's own bonus with department members, can make economic sense. Consistent with recent theory on relational contracts, we show that high-expertise managers are more likely to have lower bonus entitlements than low-expertise managers either as a reflection of other efforts to encourage cooperation and/or as an additional tool to promote working together within the department. We also show differences between high- and low-expertise managers in how they disperse the remaining bonus pool to employees.

To foster cooperation among department members, high-expertise managers allocate bonuses to subordinates to reward their contribution more equally, and the standard deviation of the contribution-adjusted bonuses across department members is consequently lower. Under this allocation rule, department members are conjectured to develop a sense of mutual sharing and are less inclined to forego helping activities (Itoh 1991). While our data prevent us from directly measuring the effect of bonus decisions on cooperation, we can assess its impact on the ultimate performance outcome. High-expertise managers who share their bonus more generously with subordinates and allocate bonuses more evenly achieve higher financial performance than all other managers.

Another important insight of our findings is that a given manager's expertise matters in understanding firm heterogeneity in management practices. Recent work has suggested that managers use discretion and judgment to engage in "informal management" (Gibbons and Kaplan 2015). Rather than managing "by the numbers" (i.e., emphasizing formal performance measures and incentive contracts), managers may implement practices that encourage employees to take noncontractible actions that benefit the firm. Our findings are consistent with the idea that 
managers differ in the way in which they rely on informal management to achieve better financial outcomes.

We use a relational contracting framework to study how managers' expertise relates to cooperation-supporting management practices and is potentially associated with performance outcomes. To test our expectations, we deliberately choose a complex contracting environment, namely, clinical units within a large hospital. In hospitals, clinical managers' expertise is a critical ingredient for organization outcomes. Managers' discretion is necessary because of difficulties in measuring clinical outcomes and prior evidence points to the importance of cooperation in performing clinical work. While we expect our study is generalizable to other complex contracting environments, we do not expect relational contracts to be important in settings where behavior can be specified unambiguously and/or where output is measurable. Nevertheless, there are numerous settings where relational contracts have an important role to play and our study speaks to how they can be built and maintained. 


\section{REFERENCES}

Abernethy, M. A., and M. Wallis. 2018. Critique of the 'manager effects' research and implications for management accounting research. Journal of Management Accounting Research Forthcoming.

Adams, R. B., M. Keloharju, and S. Knüpfer. 2014. Match Made at Birth? What Traits of a Million Swedes Tell Us about CEOs. IFN Working paper, Research Institute of Industrial Economics, Stockholm.

Angrist , J. D., and J.-S. Pischke. 2009. Mostly Harmless Econometrics: An Empiricist's Companion: Princeton University Press.

Baker, G., R. Gibbons, and K. J. Murphy. 1994. Subjective performance measures in optimal incentive contracts. The Quarterly Journal of Economics 109 (4):1125-1156.

Bandiera, O., L. Guiso, A. Prat, and R. Sadun. 2011. What do CEOs do? working paper.

Bénabou, R., and J. Tirole. 2003. Intrinsic and Extrinsic Motivation. The Review of Economic Studies 70 (3):489-520.

Bertrand, M., and A. Schoar. 2003. Managing with Style: The Effect of Managers on Firm Policies. Quarterly Journal of Economics 118 (4):1169-1208.

Bloom, N., B. Eifert, A. Mahajan, D. McKenzie, and J. Roberts. 2013. Does Management Matter? Evidence from India. The Quarterly Journal of Economics 128 (1):1-51.

Bloom, N., and J. Van Reenen. 2007. Measuring and Explaining Management Practices Across Firms and Countries. Quarterly Journal of Economics 122 (4):1351-1408.

Bloom, N., and J. Van Reenen. 2011. Chapter 19 - Human Resource Management and Productivity. In Handbook of Labor Economics, edited by C. David and A. Orley: Elsevier, 1697-1767.

Bol, J. C. 2011. The determinants and performance effects of managers' performance evaluation biases. The Accounting Review 86 (5):1549-1575.

Bol, J. C., and S. D. Smith. 2011. Spillover Effects in Subjective Performance Evaluation: Bias and the Asymmetric Influence of Controllability. The Accounting Review 86 (4):1213-1230.

Bouwens, J. A. N., and L. Van Lent. 2007. Assessing the Performance of Business Unit Managers. Journal of Accounting Research 45 (4):667-697.

Bushman, R. M., R. J. Indjejikian, and A. Smith. 1995. Aggregate Performance Measures in Business Unit Manager Compensation: The Role of Intrafirm Interdependencies. Journal of Accounting Research 33:101-128.

Cooke, F. L. 2004. Public-sector pay in China: 1949-2001. The International Journal of Human Resource Management 15 (4-5):895-916.

Demerjian, P., B. Lev, and S. McVay. 2012. Quantifying Managerial Ability: A New Measure and Validity Tests. Management Science 58 (7):1229-1248.

Ellingsen, T., and M. Johannesson. 2008. Pride and prejudice: The human side of incentive theory. American Economic Review 98 (3):990-1008.

Falk, A., and M. Kosfeld. 2006. The Hidden Costs of Control. American Economic Review 96 (5):16111630.

Gibbons, R., and R. Henderson. 2012. Relational Contracts and Organizational Capabilities. Organization Science 23 (5):1350-1364.

Gibbons, R., and R. Henderson. 2013. What do managers do? In The Handbook of Organizational Economics, edited by R. Gibbons and J. Roberts. Princeton: Princeton University Press.

Gibbons, R., and R. S. Kaplan. 2015. Formal Measures in Informal Management: Can a Balanced Scorecard Change a Culture? American Economic Review 105 (5):447-451.

Gittell, J. H. 2002. Coordinating Mechanisms in Care Provider Groups: Relational Coordination as a Mediator and Input Uncertainty as a Moderator of Performance Effects. Management Science 48 (11):1408-1426.

Gittell, J. H., K. M. Fairfield, B. Bierbaum, W. Head, R. Jackson, M. Kelly, R. Laskin, S. Lipson, J. Siliski, T. Thornhill, and J. Zuckerman. 2000. Impact of Relational Coordination on Quality of 
Care, Postoperative Pain and Functioning, and Length of Stay: A Nine-Hospital Study of Surgical Patients. Medical Care 38 (8):807-819.

Gittell, J. H., R. Seidner, and J. Wimbush. 2010. A Relational Model of How High-Performance Work Systems Work. Organization Science 21 (2):490-506.

Graham, J. R., C. R. Harvey, and M. Puri. 2013. Managerial attitudes and corporate actions. Journal of Financial Economics 109 (1):103-121.

Hamilton, B. H., J. A. Nickerson, and H. Owan. 2003. Team Incentives and Worker Heterogeneity: An Empirical Analysis of the Impact of Teams on Productivity and Participation. Journal of Political Economy 111 (3):465-497.

Helper, S., and R. Henderson. 2014. Management Practices, Relational Contracts, and the Decline of General Motors. The Journal of Economic Perspectives 28 (1):49-72.

Holmstrom, B. 1979. Moral Hazard and Observability. The Bell Journal of Economics 10 (1):74-91.

Holmstrom, B., and P. Milgrom. 1994. The Firm as an Incentive System. American Economic Review 84 (4):972-991.

Ichniowski, C., K. Shaw, and G. Prennushi. 1997. The Effects of Human Resource Management Practices on Productivity: A Study of Steel Finishing Lines. The American Economic Review 87 (3):291313.

Itoh, H. 1991. Incentives to help in multi-agent situations. Econometrica 59 (3):611-636.

Jensen, M. C., and W. H. Meckling. 1976. Theory of the firm: Managerial behavior, agency costs and ownership structure. Journal of Financial Economics 3 (4):305-360.

Kaplan, S. N., M. M. Klebanov, and M. Sorensen. 2012. Which CEO Characteristics and Abilities Matter? The Journal of Finance 67 (3):973-1007.

Keating, S. A. 1997. Determinants of divisional performance evaluation practices. Journal of Accounting and Economics 24 (3):243-273.

Knez, M., and D. Simester. 2001. Firm-Wide Incentives and Mutual Monitoring at Continental Airlines. Journal of Labor Economics 19 (4):743-772.

Levin, J. 2003. Relational Incentive Contracts. American Economic Review 93 (3):835-857.

Liu, X., and A. Mills. 2005. The effect of performance-related pay of hospital doctors on hospital behaviour: a case study from Shandong, China. Human resources for health 3 (11):1-12.

Meindl, J. R. 1989. Managing to Be Fair: An Exploration of Values, Motives, and Leadership. Administrative Science Quarterly 34 (2):252-276.

Milgrom, P., and J. Roberts. 1995. Complementarities and fit strategy, structure, and organizational change in manufacturing. Journal of Accounting and Economics 19 (2):179-208.

Mintzberg, H. 1980. Structure in 5's: A Synthesis of the Research on Organization Design. Management Science 26 (3):322-341.

Moers, F. 2005. Discretion and bias in performance evaluation: the impact of diversity and subjectivity. Accounting, Organizations and Society 30 (1):67-80.

Pizzini, M. 2010. Group-based compensation in professional service firms: An empirical analysis of medical group practices. The Accounting Review 85 (1):343-380.

Prendergast, C., and R. Topel. 1996. Favoritism in Organizations. Journal of Political Economy 104 (5):958-978.

Sliwka, D. 2007. Trust as a Signal of a Social Norm and the Hidden Costs of Incentive Schemes. American Economic Review 97 (3):999-1012.

Tabellini, G. 2008. The Scope of Cooperation: Values and Incentives. Quarterly Journal of Economics 123 (3):905-950.

Wooldridge, J. M. 2000. Introductory Economictrics: A Modern Approach. Cincinnati, OH: SouthWestern College Publishing. 


\section{Appendix A: Variable Descriptions}

\begin{tabular}{|c|c|}
\hline Variable & Description \\
\hline DepProfit ${ }_{i t}$ & $=$ the profit of department $i$ in month $t$ \\
\hline DepRev $_{i t}$ & $=$ the revenue of department $i$ in month $t$ \\
\hline DepBonPool $_{i t}$ & $\begin{array}{l}=\text { the department } i \text { 's bonus determined by the department profit } \\
\text { in month } t\end{array}$ \\
\hline & $=$ the sum of all individuals' bonuses of department $i$ in month $t$ \\
\hline DepSumSal $_{i t}$ & $=$ the sum of all individuals' salaries of department $i$ in month $t$ \\
\hline$\Delta D e p R e v_{i t}$ & $\begin{array}{l}=\text { the performance change in department revenues } \\
=\text { DepRev }_{i t+l}-\text { DepRev }_{i t}\end{array}$ \\
\hline $\operatorname{DepRev}_{i t}(\%)$ & $=$ the ratio of the next month revenues to the current revenues \\
\hline & $=\operatorname{DepRev}_{i t+1} / \operatorname{DepRev}_{i t}$ \\
\hline \multirow[t]{2}{*}{ DepRev_3mit $(\%)$} & $\begin{array}{l}=\text { the ratio of the sum of the next } 3 \text {-month revenues to the current } \\
\text { revenues }\end{array}$ \\
\hline & $=\left(\operatorname{DepRev}_{i t+1}+\operatorname{DepRev}_{i t+2}+\operatorname{DepRev}_{i t+3}\right) / \operatorname{DepRev}_{i t}$ \\
\hline \multirow[t]{3}{*}{ DepRev_6mit $(\%)$} & $\begin{array}{l}=\text { the ratio of the sum of the next 6-month revenues to the current } \\
\text { revenues }\end{array}$ \\
\hline & $=\left(\right.$ DepRev $_{i t+1}+$ DepRev $_{i t+2}+\operatorname{DepRev}_{i t+3} \operatorname{DepRev}_{i t+4+}$ \\
\hline & DepRev $_{i t+5}+$ DepRev $\left._{i t+6}\right) /$ DepRev $_{i t}$ \\
\hline \multirow[t]{2}{*}{$\Delta$ DepfProfit ${ }_{i t}$} & $=$ the performance change in departmental profits \\
\hline & $=$ DepProfit $_{i t+1}-$ DepProfit $_{i t}$ \\
\hline DepSize $_{i t}$ & $\begin{array}{l}=\text { the total number of employees including physicians and nurses } \\
\text { of department } i \text { in month } t\end{array}$ \\
\hline PhyRatio $_{i t}$ & $\begin{array}{l}=\text { the ratio of the number of physicians to nurses of department } i \\
\text { in month } t\end{array}$ \\
\hline DepBonSalRatio $_{i}$ & $\begin{array}{l}=\text { the average ratio of department } i \text { 's bonus pool to the sum of all } \\
\text { individuals' salaries of department } i \text { across the sample period }\end{array}$ \\
\hline Interdepend $_{i}$ & $=$ the index of department task interdependence \\
\hline DepMed $_{i}$ & $\begin{aligned}= & \text { an indicator variable, } 1 \text { if department } i \text { is a medical department } \\
& \text { (such as Pediatrics); otherwise } 0\end{aligned}$ \\
\hline DepSurg $_{i}$ & $\begin{aligned}= & \text { an indicator variable, } 1 \text { if department } i \text { is a surgical department } \\
& \text { (such as Cardiovascular surgery), otherwise } 0\end{aligned}$ \\
\hline HeadBon $_{\text {it }}$ & $=$ department manager $i$ 's bonus amount in month $t$ \\
\hline HeadSal $_{i t}$ & $=$ department manager $i$ 's salary in month $t$ \\
\hline HeadBonSlice $_{i t}$ & $\begin{array}{l}=\text { the manager's bonus share, the share that the manager retains } \\
\text { out of the bonus pool of department } i \text { in month } t\end{array}$ \\
\hline HeadSalSlice $_{i t}$ & $\begin{array}{l}=\text { the manager's salary share, the share of the manager's salary } \\
\text { out of the sum of all individuals' salaries of department } i \text { in } \\
\text { month } t\end{array}$ \\
\hline adjHeadBonSlice $_{i t}$ & $\begin{aligned}= & \text { the manager's contribution-adjusted bonus share of department } \\
& i \text { in month } t\end{aligned}$ \\
\hline & $\begin{array}{l}=\text { the difference between the manager's bonus share and his or } \\
\text { her salary share of department } i \text { in month } t \\
=\text { HeadBonSlice }_{i t}-\text { HeadSalSlice }_{i t}\end{array}$ \\
\hline adjHeadBon $_{i t}$ & $\begin{array}{l}=\text { the manager's bonus unexplained by his or her salary and other } \\
\text { control variables, namely the residual term of regressing each } \\
\text { individual bonus onto the salary and other control variables } \\
\text { with department fixed effects. This variable is scaled by the } \\
\text { average bonus amount of department } i \text { in month } t\end{array}$ \\
\hline $\operatorname{adjSTDSlice}_{i t}$ & $=$ the standard deviation of contribution-adjusted bonus share \\
\hline
\end{tabular}


across subordinates of department $i$ in month $t$. The contribution-adjusted bonus share is the difference between each subordinate's bonus share in the bonus pool and the corresponding salary share

equalSTDSlice $_{i t}=$ the standard deviation of subordinates' equality-adjusted bonus share of department $i$ in month $t$

$=$ the standard deviation of the difference between the bonus share and the equal bonus share (i.e., 1/DepSize $e_{i t}$ ) across subordinates of department $i$ in month $t$

STDBon $_{i t}=$ the standard deviation of subordinates' bonus of department $i$ in month $t$, which is scaled by the average bonus amount of department $i$ in month $t$

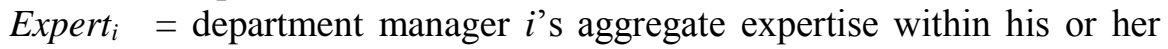
medical specialty

ExpPre $_{i}=$ department manager $i$ 's expertise on prestige factor within his or her medical specialty

$\operatorname{ExpExp}_{i}=$ department manager $i$ 's expertise on experience factor within his or her medical specialty

$E x p E d u_{i}=$ department manager $i$ 's expertise on education factor within his or her medical specialty

Expert\&Coop $_{i t}=$ high-expertise managers whose bonus decisions show full support for cooperation

$=$ an indicator variable identifying a manager who has high expertise and make both types of bonus decisions to support cooperation, 1 if (1) department manager $i$ 's expertise is above the sample median in month $t$ and (2) adjHeadBonSlice $i t$ and adjSTDSlice it are both below the sample medians in month $t$; otherwise 0

Expert \&NoCoop $_{i t}=$ high-expertise managers whose bonus decisions do not support cooperation

$=$ an indicator variable identifying a manager who has high expertise but does not make both cooperation-supporting bonus decisions, 1 if (1) department manager $i$ 's expertise is above the sample median in month $t$ and (2) both of adjHeadBonSliceit and adjSTDSlice it are not below the sample medians in month $t$; otherwise 0

NoExpert\&Coop $i t=$ low-expertise managers whose bonus decisions support cooperation

$=$ an indicator variable identifying a manager who has low expertise but makes both cooperation-supporting bonus decisions, 1 if (1) department manager $i$ 's expertise is below the sample median in month $t$ and (2) both of adjHeadBonSliceit and adjSTDSlice it are below the sample medians in month $t$; otherwise 0 


\section{Appendix B: Measurement of Managers' Expertise}

Panel A: Definitions of Expertise Indicators

\begin{tabular}{|l|l|l|}
\hline \multicolumn{1}{|c|}{$\begin{array}{c}\text { Factors of } \\
\text { Expertise }\end{array}$} & \multicolumn{1}{|c|}{ Indicator } & \multicolumn{1}{c|}{ Description } \\
\hline Prestige & Membership & $\begin{array}{l}\text { The number of memberships in medical professional } \\
\text { associations, which is shown on the hospital's website }\end{array}$ \\
\cline { 2 - 3 } & Prize & The number of prizes, which is shown on the hospital's website \\
\cline { 2 - 3 } & Star & $\begin{array}{l}\text { An indicator variable, 1 if the hospital's website indicates that } \\
\text { the individual physician is a star; 0 otherwise }\end{array}$ \\
\hline Education & EduLevel & $\begin{array}{l}\text { Educational level, ranging from doctoral degree (100) to high } \\
\text { school diploma (60) })^{21}\end{array}$ \\
\cline { 2 - 3 } & EduRanking & $\begin{array}{l}\text { Based on the top 100 medical schools in China, this indicator } \\
\text { ranges from 0 to 100. The value 100 represents the best medical } \\
\text { school. Any medical school not listed in the top 100 medical } \\
\text { schools is coded as 0. The larger value means higher ranking of } \\
\text { the school. }\end{array}$ \\
\hline Experience & Tenure & The number of years employed at the hospital \\
\cline { 2 - 3 } & Age & The individual's age \\
\hline
\end{tabular}

Panel B: Correlation among Expertise Indicators

\begin{tabular}{|c|c|c|c|c|c|c|c|}
\hline & Membership & Prize & Star & EduLevel & EduRanking & Tenure & Age \\
\hline Membership & 1 & & & & & & \\
\hline Prize & $\begin{array}{r}0.61 \\
(0.00)\end{array}$ & 1.00 & & & & & \\
\hline Star & $\begin{array}{r}0.63 \\
(0.00)\end{array}$ & $\begin{array}{r}0.79 \\
(0.00)\end{array}$ & 1.00 & & & & \\
\hline EduLevel & $\begin{array}{r}0.04 \\
(0.00)\end{array}$ & $\begin{array}{r}0.04 \\
(0.00)\end{array}$ & $\begin{array}{r}0.08 \\
(0.00)\end{array}$ & 1.00 & & & \\
\hline EduRanking & $\begin{array}{r}0.11 \\
(0.00)\end{array}$ & $\begin{array}{r}0.10 \\
(0.00)\end{array}$ & $\begin{array}{r}0.13 \\
(0.00)\end{array}$ & $\begin{array}{r}0.52 \\
(0.00)\end{array}$ & 1.00 & & \\
\hline Tenure & $\begin{array}{r}0.16 \\
(0.00)\end{array}$ & $\begin{array}{r}0.14 \\
(0.00)\end{array}$ & $\begin{array}{r}0.10 \\
(0.00)\end{array}$ & $\begin{array}{l}-0.33 \\
(0.00)\end{array}$ & $\begin{array}{l}-0.27 \\
(0.00)\end{array}$ & 1.00 & \\
\hline Age & $\begin{array}{r}0.18 \\
(0.00)\end{array}$ & $\begin{array}{r}0.17 \\
(0.00)\end{array}$ & $\begin{array}{r}0.13 \\
(0.00)\end{array}$ & $\begin{array}{l}-0.28 \\
(0.00)\end{array}$ & $\begin{array}{l}-0.21 \\
(0.00)\end{array}$ & $\begin{array}{r}0.94 \\
(0.00)\end{array}$ & 1.00 \\
\hline
\end{tabular}

$p$-values are in parentheses.

\footnotetext{
${ }^{21}$ Employees with high school diplomas work in medical support departments and have specialized skills in operating the equipment and analyzing the images.
} 
Table 1

Summary statistics for the departments $(\mathrm{N}=1,422)$

\begin{tabular}{|c|c|c|c|c|c|}
\hline Variable & Mean & Std Dev & Minimum & Median & Maximum \\
\hline DepProfit ( $¥)$ & 396,520 & 392,169 & $-1,790,577$ & 302,512 & $3,442,268$ \\
\hline DepRev ( $¥)$ & $1,802,587$ & $1,274,811$ & 37,967 & $1,555,671$ & $7,576,272$ \\
\hline DepBonPool ( $¥)$ & 116,697 & 89,448 & 1,205 & 91,949 & 681,808 \\
\hline DepSalPool ( $¥)$ & 46,060 & 27,749 & 5,124 & 39,650 & 183,489 \\
\hline$\Delta$ DepProfit $(¥)$ & 6,663 & 214,568 & $-2,414,952$ & 8,083 & $2,338,038$ \\
\hline$\Delta \operatorname{DepRev}(¥)$ & 29,959 & 413,112 & $-2,499,949$ & 9,553 & $2,052,672$ \\
\hline DepSize & 15.577 & 9.431 & 2.000 & 13.000 & 41.000 \\
\hline PhyRatio & 0.546 & 0.225 & 0.261 & 0.467 & 1.000 \\
\hline DepBonSalRatio & 2.497 & 0.498 & 1.601 & 2.471 & 3.540 \\
\hline Interdepend & 2.713 & 0.595 & 1.890 & 2.570 & 3.780 \\
\hline HeadBon ( $¥)$ & 17,426 & 7,878 & 294 & 16,343 & 63,910 \\
\hline HeadSal ( $¥)$ & 5,345 & 1,637 & 2,420 & 5,421 & 9,389 \\
\hline HeadBonSlice (\%) & 21.091 & 14.084 & 3.715 & 17.448 & 77.623 \\
\hline HeadSalSlice (\%) & 16.239 & 10.608 & 2.883 & 13.341 & 54.876 \\
\hline adjHeadBonSlice $(\%)$ & 4.857 & 5.836 & -22.055 & 3.591 & 24.509 \\
\hline adjSTDSlice & 2.017 & 1.725 & 0.310 & 1.566 & 16.922 \\
\hline Expert & 2.322 & 2.508 & -1.303 & 1.536 & 8.306 \\
\hline ExpPre & 1.505 & 2.149 & -0.276 & 0.675 & 5.802 \\
\hline $\operatorname{ExpExp}$ & 0.652 & 0.515 & -0.203 & 0.568 & 1.692 \\
\hline $\operatorname{ExpEdu}$ & 0.164 & 0.795 & -1.941 & 0.506 & 1.978 \\
\hline
\end{tabular}


Table 2

Correlation table

\begin{tabular}{|c|c|c|c|c|c|c|c|c|c|c|c|c|c|c|c|}
\hline & (a) & (b) & (c) & (d) & (e) & (f) & (g) & (h) & (i) & (j) & (k) & (l) & (m) & (n) & (o) \\
\hline (a)HeadBon & 1.00 & & & & & & & & & & & & & & \\
\hline (b)HeadSal & $\begin{array}{c}0.24 \\
(0.00)\end{array}$ & 1.00 & & & & & & & & & & & & & \\
\hline (c)HeadBonSlice & $\begin{array}{l}-0.06 \\
(0.02)\end{array}$ & $\begin{array}{l}-0.37 \\
(0.00)\end{array}$ & 1.00 & & & & & & & & & & & & \\
\hline (d)HeadSalSlice & $\begin{array}{l}-0.16 \\
(0.00)\end{array}$ & $\begin{array}{l}-0.14 \\
(0.00)\end{array}$ & $\begin{array}{c}0.93 \\
(0.00)\end{array}$ & 1.00 & & & & & & & & & & & \\
\hline (e)adjHeadBonSlice & $\begin{array}{c}0.14 \\
(0.00)\end{array}$ & $\begin{array}{l}-0.65 \\
(0.00)\end{array}$ & $\begin{array}{c}0.73 \\
(0.00)\end{array}$ & $\begin{array}{c}0.42 \\
(0.00)\end{array}$ & 1.00 & & & & & & & & & & \\
\hline (f)adjSTDSlice & $\begin{array}{l}-0.10 \\
(0.00)\end{array}$ & $\begin{array}{l}-0.28 \\
(0.00)\end{array}$ & $\begin{array}{c}0.50 \\
(0.00)\end{array}$ & $\begin{array}{c}0.45 \\
(0.00)\end{array}$ & $\begin{array}{c}0.31 \\
(0.00)\end{array}$ & 1.00 & & & & & & & & & \\
\hline (g)Expert & $\begin{array}{c}0.22 \\
(0.00)\end{array}$ & $\begin{array}{c}0.60 \\
(0.00)\end{array}$ & $\begin{array}{l}-0.22 \\
(0.00)\end{array}$ & $\begin{array}{l}-0.06 \\
(0.02)\end{array}$ & $\begin{array}{l}-0.42 \\
(0.00)\end{array}$ & $\begin{array}{l}-0.27 \\
(0.00)\end{array}$ & 1.00 & & & & & & & & \\
\hline (h)DepProfit & $\begin{array}{c}0.60 \\
(0.00)\end{array}$ & $\begin{array}{c}0.29 \\
(0.00)\end{array}$ & $\begin{array}{l}-0.41 \\
(0.00)\end{array}$ & $\begin{array}{l}-0.42 \\
(0.00)\end{array}$ & $\begin{array}{l}-0.22 \\
(0.00)\end{array}$ & $\begin{array}{l}-0.36 \\
(0.00)\end{array}$ & $\begin{array}{c}0.25 \\
(0.00)\end{array}$ & 1.00 & & & & & & & \\
\hline (i)DepRev & $\begin{array}{c}0.47 \\
(0.00)\end{array}$ & $\begin{array}{c}0.36 \\
(0.00)\end{array}$ & $\begin{array}{c}-0.57 \\
(0.00)\end{array}$ & $\begin{array}{l}-0.57 \\
(0.00)\end{array}$ & $\begin{array}{c}-0.34 \\
(0.00)\end{array}$ & $\begin{array}{l}-0.38 \\
(0.00)\end{array}$ & $\begin{array}{c}0.26 \\
(0.00)\end{array}$ & $\begin{array}{c}0.72 \\
(0.00)\end{array}$ & 1.00 & & & & & & \\
\hline (j)DepSize & $\begin{array}{c}0.20 \\
(0.00)\end{array}$ & $\begin{array}{c}0.31 \\
(0.00)\end{array}$ & $\begin{array}{l}-0.76 \\
(0.00)\end{array}$ & $\begin{array}{l}-0.74 \\
(0.00)\end{array}$ & $\begin{array}{l}-0.48 \\
(0.00)\end{array}$ & $\begin{array}{l}-0.52 \\
(0.00)\end{array}$ & $\begin{array}{c}0.14 \\
(0.00)\end{array}$ & $\begin{array}{c}0.57 \\
(0.00)\end{array}$ & $\begin{array}{c}0.65 \\
(0.00)\end{array}$ & 1.00 & & & & & \\
\hline (k)PhyRatio & $\begin{array}{l}-0.07 \\
(0.01)\end{array}$ & $\begin{array}{l}-0.29 \\
(0.00)\end{array}$ & $\begin{array}{c}0.62 \\
(0.00)\end{array}$ & $\begin{array}{c}0.62 \\
(0.00)\end{array}$ & $\begin{array}{c}0.37 \\
(0.00)\end{array}$ & $\begin{array}{c}0.30 \\
(0.00)\end{array}$ & $\begin{array}{l}-0.02 \\
(0.35)\end{array}$ & $\begin{array}{l}-0.18 \\
(0.00)\end{array}$ & $\begin{array}{c}-0.46 \\
(0.00)\end{array}$ & $\begin{array}{l}-0.56 \\
(0.00)\end{array}$ & 1.00 & & & & \\
\hline (1)DepBonSalRatio & $\begin{array}{c}0.40 \\
(0.00)\end{array}$ & $\begin{array}{l}-0.03 \\
(0.30)\end{array}$ & $\begin{array}{c}0.19 \\
(0.00)\end{array}$ & $\begin{array}{c}0.21 \\
(0.00)\end{array}$ & $\begin{array}{c}0.08 \\
(0.00)\end{array}$ & $\begin{array}{c}0.10 \\
(0.00)\end{array}$ & $\begin{array}{c}0.14 \\
(0.00)\end{array}$ & $\begin{array}{c}0.31 \\
(0.00)\end{array}$ & $\begin{array}{c}0.13 \\
(0.00)\end{array}$ & $\begin{array}{c}0.06 \\
0.0289\end{array}$ & $\begin{array}{c}0.34 \\
(0.00)\end{array}$ & 1.00 & & & \\
\hline (m)Interdepend & $\begin{array}{c}0.19 \\
(0.00)\end{array}$ & $\begin{array}{l}-0.02 \\
(0.40)\end{array}$ & $\begin{array}{c}0.09 \\
(0.00)\end{array}$ & $\begin{array}{c}0.11 \\
(0.00)\end{array}$ & $\begin{array}{c}0.02 \\
(0.45)\end{array}$ & $\begin{array}{c}0.05 \\
(0.04)\end{array}$ & $\begin{array}{l}-0.07 \\
(0.01)\end{array}$ & $\begin{array}{c}0.24 \\
(0.00)\end{array}$ & $\begin{array}{c}0.09 \\
0.0007\end{array}$ & $\begin{array}{c}0.13 \\
(0.00)\end{array}$ & $\begin{array}{c}0.22 \\
(0.00)\end{array}$ & $\begin{array}{c}0.53 \\
(0.00)\end{array}$ & 1.00 & & \\
\hline (n)DepMed & $\begin{array}{l}-0.14 \\
(0.00)\end{array}$ & $\begin{array}{c}0.11 \\
(0.00)\end{array}$ & $\begin{array}{l}-0.19 \\
(0.00)\end{array}$ & $\begin{array}{l}-0.20 \\
(0.00)\end{array}$ & $\begin{array}{l}-0.10 \\
(0.00)\end{array}$ & $\begin{array}{l}-0.15 \\
(0.00)\end{array}$ & $\begin{array}{l}-0.05 \\
(0.04)\end{array}$ & $\begin{array}{l}-0.06 \\
(0.04)\end{array}$ & $\begin{array}{c}0.19 \\
(0.00)\end{array}$ & $\begin{array}{c}0.11 \\
(0.00)\end{array}$ & $\begin{array}{l}-0.40 \\
(0.00)\end{array}$ & $\begin{array}{l}-0.45 \\
(0.00)\end{array}$ & $\begin{array}{l}-0.61 \\
(0.00)\end{array}$ & 1.00 & \\
\hline (o)DepSurg & $\begin{array}{c}0.06 \\
(0.02) \\
\end{array}$ & $\begin{array}{l}-0.08 \\
(0.00) \\
\end{array}$ & $\begin{array}{l}-0.15 \\
(0.00) \\
\end{array}$ & $\begin{array}{l}-0.17 \\
(0.00) \\
\end{array}$ & $\begin{array}{l}-0.06 \\
(0.02) \\
\end{array}$ & $\begin{array}{l}-0.06 \\
(0.03) \\
\end{array}$ & $\begin{array}{c}0.01 \\
(0.68) \\
\end{array}$ & $\begin{array}{c}0.02 \\
(0.44) \\
\end{array}$ & $\begin{array}{c}-0.07 \\
(0.01) \\
\end{array}$ & $\begin{array}{c}0.08 \\
(0.00) \\
\end{array}$ & $\begin{array}{l}-0.07 \\
(0.01) \\
\end{array}$ & $\begin{array}{c}0.06 \\
(0.02) \\
\end{array}$ & $\begin{array}{c}0.18 \\
(0.00) \\
\end{array}$ & $\begin{array}{l}-0.75 \\
(0.01) \\
\end{array}$ & 1.00 \\
\hline
\end{tabular}

This table presents Pearson correlation coefficients among the variables used in the analyses. The $p$-values are in parentheses. Appendix A describes the variables. 
Table 3

Expertise and managers' bonus

(1)

(2)

(3)

(4)

Variables adjHeadBonSlice

HeadBonSlice

adjHeadBon

adjHeadBonSlice

$\begin{array}{cccc}\text { Expert } & -0.868 * * * & -0.902 * * * & -0.119 * * \\ & (0.218) & (0.221) & (0.046)\end{array}$

ExpPre

$-0.678 * *$

(0.269)

$\operatorname{Exp} \operatorname{Exp}$

$-2.189 *$

(1.160)

$\operatorname{ExpEdu}$

$-1.355$

(0.901)

HeadSalSlice

$0.376^{*}$

(0.204)

$\overline{\text { HeadSalSlice }}$

$1.097 * * *$

DepProfit

$6.761 * *$

(0.106)

(2.861)

$\overline{\text { DepProfit }}$

$-8.776^{*}$

(5.157)

DepSize

$-0.301$

(0.299)

$\overline{\text { DepSize }}$

$-0.105$

(0.085)

PhyRatio

9.067

(10.247)

$\overline{\text { PhyRatio }}$

2.795

$6.411 * * *$

$6.761 * *$

(2.334)

(2.861)

$-5.370$

$1.954 * *$

$-10.182 * *$

(5.846)

(0.887)

(5.005)

$-0.915^{* * *}$

$-0.301$

(0.318)

$(0.299)$

$-0.069$

(0.097)

$-0.000$

$-0.090$

(0.023)

(0.078)

$20.210^{* *}$

(8.137)

(4.448)

DepBonSalRatio

$2.200 * *$

(0.878)

2.585

1.241

9.067

(10.247)

(4.528)

(1.476)

2.803

1.736

$0.539 * * *$

(4.224)

(1.090)

(0.189)

1.499

$-1.356$

0.105

(1.012)

Interdepend

$-1.361$

(1.298)

(1.349)

(0.463)

$-1.396$

DepMed

$-2.006$

(3.454)

$-1.187$

0.991

(1.353)

(3.450)

(1.204)

$-2.337$

$-0.371$

0.791

(4.369)

DepSurg

$-1.306$

(2.069)

(0.604)

$-1.797$

(2.315)

3.508

(3.129)

Constant

5.715

(7.851)

$-2.628$

9.031

(3.010)

(8.561)

\begin{tabular}{ll}
\hline Model & RCE \\
Observations & 1,422 \\
Fixed effects & Year
\end{tabular}

\section{RCE}

1,422

Year

OLS
1,422
Year

Year

RCE

1,422

Year 


\begin{tabular}{lcccc} 
Wald $\chi^{2}$ & 711.81 & $3,783.65$ & - & 688.07 \\
$\begin{array}{l}\text { Log pseudo } \\
\text { likelihood }\end{array}$ & $-3,782.51$ & $-3,677.36$ & - & $-3,781.69$ \\
\hline \multicolumn{5}{c}{ DiscBonus $_{i t}=\gamma$ Expert $_{i}+\boldsymbol{X}_{i t}^{\prime} \beta+\overline{\boldsymbol{X}}_{i}^{\prime} \delta+\eta_{t}+\varepsilon_{i t}\left(1^{\prime}\right)$}
\end{tabular}

This table presents an analysis of the association between the managers' expertise and their decisions in allocating a bonus to themselves with various specifications using Equation (1'). As an alternative to department fixed effects, we apply random correlated effects by including the department (time series) averages of the time-varying variables as additional regressors that are correlated with the time-constant unobserved department characteristics. To distinguish the between estimates from the within estimates, we denote the department time-series averages of control variables with the upper bar (e.g., DepProf $l t$ ). The coefficients of upper-barred variables capture the between estimates and the others present within estimates. Columns 1 and 4 use the department head's contribution-adjusted bonus share as the dependent variable and hence do not control for the manager's contribution (i.e., salary). Column 2 uses the department manager's bonus share as the dependent variable and controls for the manager's contribution, measured as the manager's salary share. For the dependent variable in column 3, we first run the bonus regression and scale the residual terms for the department manager by the department's average bonus amount. Please refer to the description of adjHeadBon in Appendix A for the bonus regression. Since we have accounted for the manager's contribution in the bonus regression model, we do not include a control variable for the manager's contribution in column 3. Reported in columns 1, 2, and 4 are the coefficients from Equation (1') using random correlated effects and column 3 presents the coefficient estimates from Equation (1) using pooled OLS regressions. The standard errors clustered by department are reported in parentheses. Two-tailed statistical tests are computed for all variables. *, **, and *** represent statistical significance at $10 \%, 5 \%$, and $1 \%$, respectively. 
Table 4

Expertise and the distribution of bonus payment across subordinates

(1)

Variables

$\begin{array}{cc} & -0.165 * * * \\ \text { Expert } & (0.063)\end{array}$

ExpPre

$\operatorname{ExpExp}$

$\operatorname{ExpEdu}$

DepProfit

$\overline{\text { DepProfit }}$

DepSize

$\overline{\text { DepSize }}$

PhyRatio

$\overline{\text { PhyRatio }}$

DepBonSalRatio

Interdepend

DepMed

DepSurg

Constant

$-6.838 * * *$

(2.081)

$-0.094$

(0.061)

$-0.024$

(0.025)

0.044

(2.288)

$-1.949 *$

(1.096)

$0.682 *$

(0.361)

$-0.590 * *$

(0.295)

(0.738)

(0.692)

$8.659 * * *$
(2) adjSTDSlice
(3) equalSTDSlice

$-0.029$

(0.038)

$-0.016$

(0.069)

$-0.319 *$

(0.193)

$-0.745^{* * *}$

(0.228)

$\begin{array}{cc}0.222 & 0.222 \\ (0.350) & (0.350)\end{array}$

$-3.512 * * *$

$-2.895 * * *$

(2.016)
$-6.734 * * *$

(1.929)

$-0.094$

(0.061)

$-0.038$

(0.025)

0.044

(2.288)

$-2.204 * *$

(0.859)

$0.562 * *$

(0.265)

$-0.328$

(0.327)

$-2.319 * * *$

(0.803)

$-2.056 * * *$

(0.682)

$7.038 * * *$

(2.371)
(4)

STDBon

0.005

(0.006)

$\begin{array}{cc}0.194 & 0.030 \\ (0.371) & (0.053) \\ -2.173 * * & 0.097 \\ (1.056) & (0.155) \\ -0.058 & 0.009 \\ (0.059) & (0.008) \\ -0.041 * * * & 0.003 * \\ (0.012) & (0.002) \\ 2.630 & 0.052 \\ (2.513) & (0.235) \\ 0.331 & -0.090 \\ (0.865) & (0.096) \\ 0.019 & -0.054 \\ (0.280) & (0.036) \\ -0.388 * * & -0.054 * \\ (0.181) & (0.030) \\ -1.311 * * & -0.150 * \\ (0.536) & (0.081) \\ -0.836 * & -0.098 \\ (0.430) & (0.060) \\ 4.859 * * * & 0.497 * * * \\ (1.010) & (0.160)\end{array}$

\begin{tabular}{lcccc}
\hline Model & RCE & RCE & RCE & RCE \\
Observations & 1,375 & 1,375 & 1,375 & 1,375 \\
Fixed effects & Year & Year & Year & Year \\
Wald $\chi^{2}$ & 347.18 & 531.34 & 315.53 & 341.67 \\
Log pseudo & & & & \\
likelihood & $-2,094.57$ & $-2,088.67$ & $-2,034.90$ & $1,356.35$ \\
\hline
\end{tabular}

DiscBonus $_{i t}=\gamma$ Expert $_{i}+\boldsymbol{X}_{i t}^{\prime} \beta+\overline{\boldsymbol{X}}_{i}^{\prime} \delta+\eta_{t}+\varepsilon_{i t}\left(1^{\prime}\right)$ 
This table presents an analysis of the association between the department managers' expertise and their decisions in distributing bonus across subordinates with various specifications using Equation ( $\left.1^{\prime}\right)$. As an alternative to department fixed effects, we apply random correlated effects by including the department (time series) averages of the time-varying variables as additional regressors that are correlated with the time-constant unobserved department characteristics. To distinguish the between estimates from the within estimates, we denote the department time-series averages of control variables with the upper bar (e.g., DepProfit $)$. The coefficients of upper-barred variables capture the between estimates and the others present within estimates. Columns 1 and 2 adjust subordinates' contribution based on their salaries, and columns 3 and 4 use equality (i.e., equal share) as an alternative approach that treats each subordinate as making an equal contribution to the department. We use as the dependent variable the standard deviation of subordinates' contribution-adjusted bonus share in columns 1 and 2. Column 3 uses the standard deviation of subordinates' equality-adjusted bonus share, which is the difference between the bonus share and the equal share (i.e., 1/DepSize). Column 4 takes the scaled standard deviation (i.e., coefficient of variation) of yuan-based bonus across subordinates. Reported are the coefficients from Equation (1') using random correlated effect regressions with standard errors clustered by department in parentheses. Two-tailed statistical tests are conducted for all variables. *, **, and *** represent statistical significance at $10 \%, 5 \%$, and $1 \%$, respectively. 
Table 5

Expertise and discretionary bonus decisions using a reduced sample

Variables adjHeadBonSlice

adjSTDSlice

\begin{tabular}{|c|c|c|}
\hline Expert & $\begin{array}{c}-0.765 * * \\
(0.278)\end{array}$ & $\begin{array}{c}-0.157 * * \\
(0.072)\end{array}$ \\
\hline DepProfit & $\begin{array}{c}-10.850 * \\
(5.801)\end{array}$ & $\begin{array}{c}-7.039 * * \\
(2.581)\end{array}$ \\
\hline DepSize & $\begin{array}{c}-0.092 \\
(0.095)\end{array}$ & $\begin{array}{l}-0.019 \\
(0.024)\end{array}$ \\
\hline PhyRatio & $\begin{array}{c}4.793 \\
(5.486)\end{array}$ & $\begin{array}{l}-1.898 \\
(1.334)\end{array}$ \\
\hline DepBonSalRatio & $\begin{array}{c}1.961 \\
(1.385)\end{array}$ & $\begin{array}{c}0.805 \\
(0.479)\end{array}$ \\
\hline Interdepend & $\begin{array}{c}-0.761 \\
(1.675)\end{array}$ & $\begin{array}{l}-0.640 * \\
(0.334)\end{array}$ \\
\hline DepMed & $\begin{array}{l}-2.143 \\
(4.430)\end{array}$ & $\begin{array}{c}-3.206 * * * \\
(0.970)\end{array}$ \\
\hline DepSurg & $\begin{array}{l}-2.078 \\
(2.934)\end{array}$ & $\begin{array}{c}-2.605 * * * \\
(0.890)\end{array}$ \\
\hline Constant & $\begin{array}{c}6.071 \\
(10.184)\end{array}$ & $\begin{array}{c}7.076^{* * *} \\
(1.903)\end{array}$ \\
\hline Model & OLS & OLS \\
\hline Observations & 34 & 33 \\
\hline adjR-squared & 0.601 & 0.730 \\
\hline
\end{tabular}

This table presents an analysis of the association between the managers' expertise and their decisions in allocating bonus to themselves and in distributing bonus among subordinates using Equation (1). All the variables are the department averages, so the analysis is on a reduced cross-sectional sample. Column 1 uses the manager's contribution-adjusted bonus as the dependent variable, and column 2 uses the distribution of subordinates' contribution-adjusted bonus as the dependent variable. Reported in columns 1 and 2 are the coefficients from Equation (1) using pooled OLS regressions. The standard errors are reported in parentheses. Two-tailed statistical tests are computed for all variables. *, **, and *** represent statistical significance at $10 \%, 5 \%$, and $1 \%$, respectively. 
Table 6 Performance improvement, managers' expertise, and bonus decisions

Panel A. Different groups of managers based on the level of their expertise and cooperation-supporting bonus decisions

\begin{tabular}{|c|c|c|c|c|c|c|}
\hline VARIABLES & $\begin{array}{c}(1) \\
\Delta \text { DepRev } \\
\text { (per emp) }\end{array}$ & $\begin{array}{c}(2) \\
\Delta \text { DepRev }\end{array}$ & $\begin{array}{c}(3) \\
\text { DepRev } \\
(\%)\end{array}$ & $\begin{array}{c}(4) \\
\text { DepRev_3m } \\
(\%)\end{array}$ & $\begin{array}{c}(5) \\
\text { DepRev_6m } \\
(\%)\end{array}$ & $\begin{array}{c}\text { (6) } \\
\Delta \text { DepProfit }\end{array}$ \\
\hline Expert\&Coоp & $\begin{array}{c}0.704 * * * \\
(0.250)\end{array}$ & $\begin{array}{c}0.178 * * \\
(0.075)\end{array}$ & $\begin{array}{c}0.031 * * \\
(0.013)\end{array}$ & $\begin{array}{c}0.149 * * \\
(0.062)\end{array}$ & $\begin{array}{c}0.323 * * \\
(0.136)\end{array}$ & $\begin{array}{c}0.089 * * * \\
(0.025)\end{array}$ \\
\hline Expert\&NoCoop & $\begin{array}{l}-0.205 \\
(0.304)\end{array}$ & $\begin{array}{c}0.012 \\
(0.041)\end{array}$ & $\begin{array}{c}-0.009 \\
(0.008)\end{array}$ & $\begin{array}{l}-0.021 \\
(0.036)\end{array}$ & $\begin{array}{l}-0.111 \\
(0.098)\end{array}$ & $\begin{array}{l}0.024^{*} \\
(0.013)\end{array}$ \\
\hline NoExpert\&Coop & $\begin{array}{c}0.695 \\
(0.488)\end{array}$ & $\begin{array}{c}0.077 \\
(0.113)\end{array}$ & $\begin{array}{c}0.024 \\
(0.022)\end{array}$ & $\begin{array}{c}0.125 \\
(0.094)\end{array}$ & $\begin{array}{c}0.185 \\
(0.222)\end{array}$ & $\begin{array}{c}0.093 * * * \\
(0.022)\end{array}$ \\
\hline $\begin{array}{l}\text { Model } \\
\text { Fixed effect } \\
\text { Observations }\end{array}$ & $\begin{array}{l}\text { RCE } \\
\text { Year } \\
1,388\end{array}$ & $\begin{array}{l}\text { RCE } \\
\text { Year } \\
1,388\end{array}$ & $\begin{array}{l}\mathrm{RCE} \\
\text { Year } \\
1,388\end{array}$ & $\begin{array}{l}\text { RCE } \\
\text { Year } \\
1,320\end{array}$ & $\begin{array}{l}\text { RCE } \\
\text { Year } \\
1,218\end{array}$ & $\begin{array}{l}\mathrm{RCE} \\
\text { Year } \\
1,388\end{array}$ \\
\hline $\begin{array}{l}\text { Wald } \chi^{2} \\
\text { Log pseudo } \\
\text { likelihood }\end{array}$ & -4945.59 & 485.42 & 117.79 & -1203.73 & -1991.05 & 200.62 \\
\hline
\end{tabular}

Panel B. Test of hypothesis H3

\begin{tabular}{|c|c|c|c|c|c|c|}
\hline VARIABLES & $\begin{array}{c}(1) \\
\Delta \text { DepRev } \\
\text { (per emp) }\end{array}$ & $\begin{array}{c}(2) \\
\Delta \text { DepRev }\end{array}$ & $\begin{array}{c}(3) \\
\text { DepRev } \\
(\%)\end{array}$ & $\begin{array}{c}(4) \\
\text { DepRev_3m } \\
(\%)\end{array}$ & $\begin{array}{c}(5) \\
\text { DepRev_6m } \\
(\%) \\
\end{array}$ & $\begin{array}{c}\text { (6) } \\
\Delta \text { DepProfit }\end{array}$ \\
\hline Expert\&Coop & $\begin{array}{c}0.680 * * \\
(0.289)\end{array}$ & $\begin{array}{c}0.146 * * * \\
(0.047)\end{array}$ & $\begin{array}{c}0.026 * * * \\
(0.008)\end{array}$ & $\begin{array}{c}0.114 * * * \\
(0.039)\end{array}$ & $\begin{array}{c}0.316 * * * \\
(0.081)\end{array}$ & $\begin{array}{c}0.046^{* *} \\
(0.021)\end{array}$ \\
\hline $\begin{array}{l}\text { Model } \\
\text { Controls } \\
\text { Fixed effect } \\
\text { Observations }\end{array}$ & $\begin{array}{c}\text { RCE } \\
\text { Included } \\
\text { Year } \\
1,388\end{array}$ & $\begin{array}{c}\text { RCE } \\
\text { Included } \\
\text { Year } \\
1,388\end{array}$ & $\begin{array}{c}\text { RCE } \\
\text { Included } \\
\text { Year } \\
1,388\end{array}$ & $\begin{array}{c}\text { RCE } \\
\text { Included } \\
\text { Year } \\
1,320\end{array}$ & $\begin{array}{c}\text { RCE } \\
\text { Included } \\
\text { Year } \\
1,218\end{array}$ & $\begin{array}{c}\text { RCE } \\
\text { Included } \\
\text { Year } \\
1,388\end{array}$ \\
\hline $\begin{array}{l}\text { Wald } \chi^{2} \\
\text { Log pseudo } \\
\text { likelihood }\end{array}$ & 163.99 & 966.82 & 133.56 & 95.51 & 95.76 & 296.11 \\
\hline S & cpert\&C & $p)_{i t}+\lambda_{2} \mathbf{1}$ & - & $o o p)_{i t}+$ & NoExper & $o o p)_{i t}+$ \\
\hline
\end{tabular}

The table in panel A presents the analyses on the difference in performance improvement between different groups of managers which are characterized jointly by their expertise and the degree of their cooperation-supporting bonus decisions. The three indicator variables in Panel A, Expert\&Coop, Expert\&NoCoop, and NoExpert\&Coop, represent (1) high-expertise managers whose bonus decisions 
support cooperation, (2) high-expertise managers whose bonus decisions do not support cooperation, and (3) low-expertise managers whose bonus decisions support cooperation, respectively. Panel B includes only one indicator variable, Expert\&Coop, and takes all other managers as the reference group. Columns 1-3 report the estimates for regressions that use the change in department revenues in the next month as the dependent variable whereas columns 4 and 5 use the change in department revenues in the next 3 and 6 months, respectively. Column 6 presents a regression using the change in department profits of the next month as the dependent variable. Reported are the coefficients from Equation (2) with standard errors clustered by department in parentheses using random correlated effect regressions. Two-tailed statistical tests are conducted for all variables. *,**, and *** represent statistical significance at $10 \%, 5 \%$, and $1 \%$, respectively. 